\title{
Shear crack formation and propagation in fiber reinforced cementitious composites (FRCC)
}

Paegle, leva; Fischer, Gregor

Published in:

Proceedings of the Sixth International Workshop on High Performance Fiber Reinforced Cement Composites

Publication date:

2011

Document Version

Publisher's PDF, also known as Version of record

Link back to DTU Orbit

Citation (APA):

Paegle, I., \& Fischer, G. (2011). Shear crack formation and propagation in fiber reinforced cementitious composites (FRCC). In Proceedings of the Sixth International Workshop on High Performance Fiber Reinforced Cement Composites (pp. 221-228)

\section{General rights}

Copyright and moral rights for the publications made accessible in the public portal are retained by the authors and/or other copyright owners and it is a condition of accessing publications that users recognise and abide by the legal requirements associated with these rights.

- Users may download and print one copy of any publication from the public portal for the purpose of private study or research.

- You may not further distribute the material or use it for any profit-making activity or commercial gain

- You may freely distribute the URL identifying the publication in the public portal

If you believe that this document breaches copyright please contact us providing details, and we will remove access to the work immediately and investigate your claim 


\title{
Shear crack formation and propagation in fiber reinforced cementitious composites (FRCC)
}

\author{
I. Paegle, G. Fischer \\ Technical University of Denmark, Department of Civil Engineering, Kgs. Lyngby, Denmark
}

\begin{abstract}
Knowledge of the mechanisms controlling crack formation, propagation and failure of FRCC under shear loading is currently limited. This paper presents a study that utilized photogrammetry to monitor the shear deformations of two FRCC materials and ordinary concrete (OC). Multiple shear cracks and strain hardening of both FRCC materials was observed under shear loading. The influence of fibers, fiber type, including polyvinyl alcohol (PVA) and polypropylene (PP) fibers, and shear crack angle were investigated. Based upon photogrammetric results, fundamental descriptions of shear crack opening/sliding and subsequent failure are presented.
\end{abstract}

\section{Introduction}

There are numerous models available to predict the shear capacity of FRCC [1-3]. However, understanding of the controlling, fundamental mechanisms is lacking, resulting in limited applicability of particular models. Some models may provide accurate predictions for one material and/or load configuration, but minor changes may result in inaccurate predictions. This paper proposes a description of the fundamental mechanisms of shear deformation and failure in FRCC without conventional steel reinforcement in form of stirrups. The proposed mechanisms may be useful in creating a 'universal' model for a wider range of FRCC materials and shear load configurations.

\section{Materials and experimental methods}

The experimental program consists of shear beams, shown in Fig. 1, and corresponding tension and compression specimens of three materials:

- FRCC beams with randomly distributed PVA fibers (PVA-FRCC);

- FRCC beams with randomly distributed PP fibers (PP-FRCC);

- Ordinary concrete (OC). 
Table 1. Properties of PVA and PP fibers

\begin{tabular}{cccccccc}
\hline $\begin{array}{c}\text { Fiber } \\
\text { (Trade name) }\end{array}$ & $\begin{array}{c}\text { Beam } \\
\text { description }\end{array}$ & $\begin{array}{c}\text { Fiber } \\
\text { type }\end{array}$ & $\begin{array}{c}\varnothing \\
{[\mu \mathrm{m}]}\end{array}$ & $\begin{array}{c}\mathrm{L} \\
{[\mathrm{mm}]}\end{array}$ & $\begin{array}{c}\mathrm{f}_{\mathrm{t}} \\
{[\mathrm{MPa}]}\end{array}$ & $\begin{array}{c}\mathrm{E} \\
{[\mathrm{GPa}]}\end{array}$ & $\begin{array}{c}\text { Strain capacity } \\
{[\%]}\end{array}$ \\
\hline REC 15 & PVA-FRCC & PVA & 40 & 8 & 1560 & 40 & 6.5 \\
Innegra & PP-FRCC & PP & 45 & 16 & 550 & 13.4 & 8 \\
\hline
\end{tabular}

The properties of PVA and PP fibers used in this study are listed in Table 1. For PVA-FRCC and PP-FRCC beams mortar consisting of fly ash, cement, water, sand (max. grain size $0.18 \mathrm{~mm}$ ), quartz powder and fibers (2 vol. \%) was used. Ordinary concrete consisted of cement, water, fine and coarse aggregates (max. aggregate size $16 \mathrm{~mm}$ ). The concrete mixture was designed to have a compressive strength similar to that of PVA-FRCC and PP-FRCC. Specimens were demolded after 24 to 48 hours after casting and were air-cured for approximately at least 28 days prior to testing.

Tensile stress-strain responses of PVA-FRCC and PP-FRCC were determined using 'dogbone' specimens with a representative cross section of $25 \mathrm{~mm} \times 50 \mathrm{~mm}$. Deformation controlled tensile tests $(0.5 \mathrm{~mm} / \mathrm{min}$ loading rate) were conducted with linear variable differential transformers (LVDT's) measuring the tensile deformations and a photogrammetric data acquisition system measuring crack deformations. Splitting tensile testing, according to EN 12390-6 [4], was carried out for $\mathrm{OC}$ with a loading rate of $1.57 \mathrm{kN} / \mathrm{s}$. The photogrammetry equipment captures images of the representative section of the specimen at a rate of $1 \mathrm{~Hz}$ and through post-processing of the captured images of the deformed specimen surface deformations were determined. Additional information on 'dogbone' specimens and the photogrammetric data acquisition system is available elsewhere [5].

Fig. 1 illustrates the specimen geometry and loading configuration, which is similar to the Ohno shear beam [6] used to investigate shear cracking under various crack angles. Longitudinal reinforcement, which is necessary to avoid flexural failure of the beams but may have an effect on the shear cracking behavior (location, angle), was provided by carbon fiber reinforced polymer plates glued on thetop and bottom faces of the specimen (Fig. 1(a)).

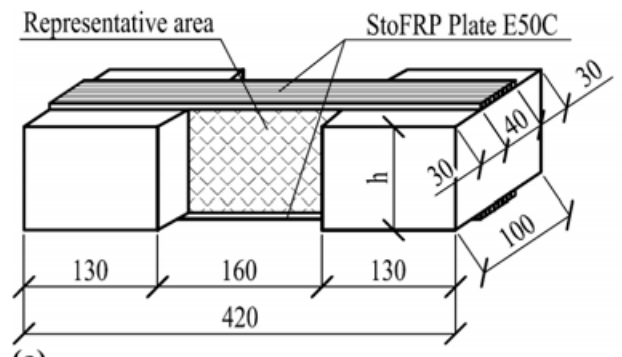

(a)

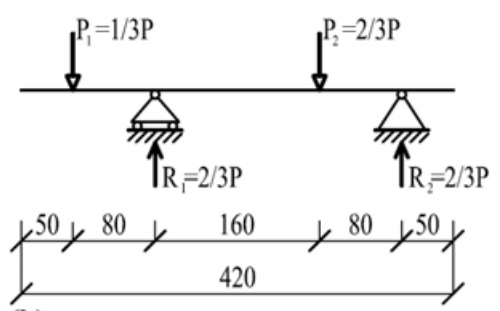

(b)

Fig. 1. Shear test setup. Beam's geometry: (a) three-dimensional view; (b) schematic load configuration 
Table 2. Specimen height and corresponding targeted and measured shear angles

\begin{tabular}{lccccccc}
\hline \multicolumn{1}{c}{ Beam } & $\begin{array}{c}\text { Height, Targeted Measured } \\
\mathrm{h} \\
{[\mathrm{mm}]}\end{array}$ & $\begin{array}{c}\text { cr. angle } \\
{[\mathrm{deg}]}\end{array}$ & $\begin{array}{c}\text { cr. angle } \\
{[\mathrm{deg}]}\end{array}$ & $\begin{array}{c}\text { Beamht, Targeted Measured } \\
\mathrm{h} \\
{[\mathrm{mm}]}\end{array}$ & $\begin{array}{c}\text { cr. angle } \\
\text { [deg] }]\end{array}$ & $\begin{array}{c}\text { cr. angle } \\
{[\mathrm{deg}]}\end{array}$ \\
\hline PVA-FRCC60 & 60 & 22 & $30 \pm 5$ & PVA-FRCC150 & 150 & 45 & $45 \pm 5$ \\
PP-FRCC60 & 60 & 22 & $30 \pm 5$ & PP-FRCC150 & 150 & 45 & $45 \pm 5$ \\
OC 60 & 60 & 22 & 26 & OC 150 & 150 & 45 & $45 \pm 2$ \\
PVA-FRCC100 & 100 & 34 & $35 \pm 5$ & PVA-FRCC170 & 170 & 49 & $50 \pm 5$ \\
PP-FRCC100 & 100 & 34 & $35 \pm 5$ & PP-FRCC170 & 170 & 49 & $50 \pm 3$ \\
OC 100 & 100 & 34 & $40 \ldots 45$ & OC 170 & 170 & 49 & $50 \pm 3$ \\
\hline
\end{tabular}

This configuration restricts formation of flexural cracks, provides minimal addition to shear capacity, and has a reduced influence on the shear capacity compared to embedded rebar. Variations in crack angle were achieved by changing the specimen height while other parameters remained constant. Specimen height and comparison of targeted and measured shear crack angles are shown in Table 2. Beams were loaded in a displacement-controlled procedure with a loading rate of 0.02 $\mathrm{mm} / \mathrm{s}$. Shear crack formation and development was monitored using photogrammetry.

\section{Results}

Typical tensile stress-strain relationships for PVA-FRCC and PP-FRCC are shown in Fig. 2 (a) and (b), respectively. The PVA-FRCC can be considered an Engineered Cementitious Composites (ECC), which is a type of fiber reinforced cementitious material characterized by multiple cracking and strain hardening under uniaxial tension [7-9]. The average first cracking strength taken from six test specimens was 4.1 MPa and 3.2 MPa for PVA-FRCC and PP-FRCC, respectively. Average ultimate tensile strength for the PVA-FRCC, PP-FRCC and OC were 4.5 $\mathrm{MPa}, 4.1 \mathrm{MPa}$ and 4.1 MPa, respectively, while the compressive strength was 45.9 $\mathrm{MPa}, 48.8 \mathrm{MPa}$ and 56.0 MPa, respectively.

Fig. 3 shows shear cracks that developed in specimen with a height of $100 \mathrm{~mm}$ under shear loading for the different materials. The most apparent benefit of FRCC compared to conventional concrete $(\mathrm{OC})$ is the formation of multiple shear cracking in FRCC resulting in smaller crack widths at the ultimate limit state. Fig. 4 shows typical crack development behavior in terms of crack opening and sliding as measured by photogrammetry for the three tested materials. The schematic in Fig. 4(a) illustrates the two components (opening and sliding) that contribute to the total crack deformation. Opening and sliding were determined by fixing two virtual markers on opposing sides of a single crack in the captured images and subsequently obtaining the relative displacements between them. All graphs show the crack opening and sliding relationships of the 'failure' crack which do not necessarily coincide with the first formed shear crack. 

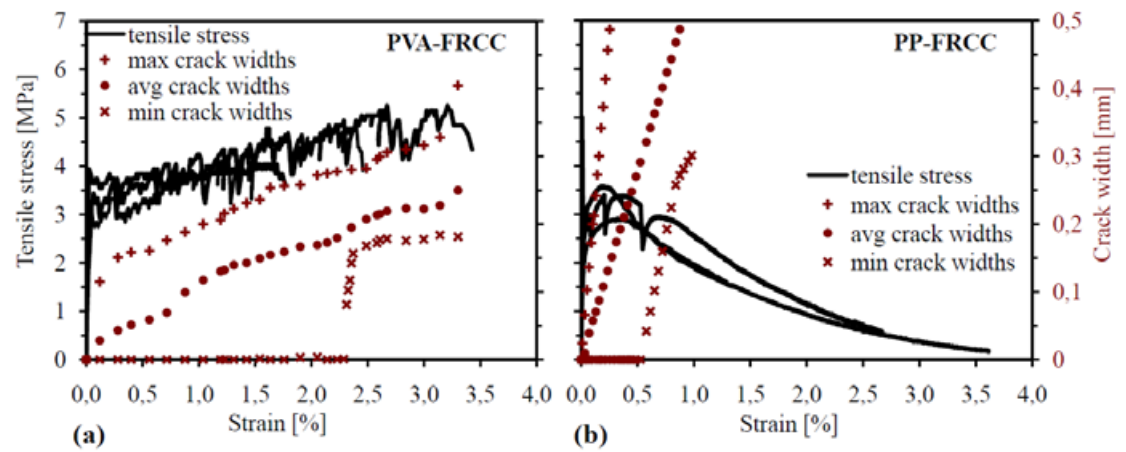

Fig. 2. Tensile properties of: (a) PVA-FRCC and (b) PP-FRCC

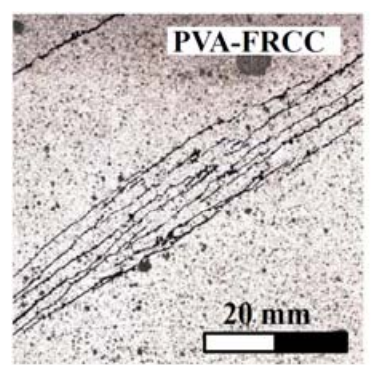

(a)

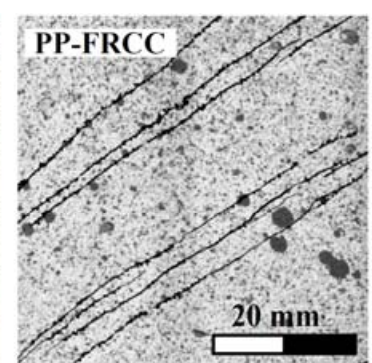

(b)

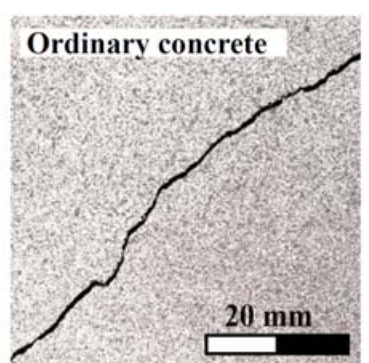

(c)

Fig. 3. Shear cracks in PVA (a) and PP (b) FRCCs and in ordinary concrete(c) beams

The graphs in the left column of Fig. 4 show results for beams with shear crack angles between $25-35^{\circ}$ ( 60 and $100 \mathrm{~mm}$ beam height), while the right column shows results from beams with $40-50^{\circ}$ shear angles $(150$ and $170 \mathrm{~mm}$ beam height).

The effect of fibers is illustrated by comparing results presented in the left column of Fig. 4. Fig. 4(e) shows that the shear stress in OC decreases immediately after crack formation (failure was not completely brittle due to CFRP plates), whereas an increase in shear stress after crack formation due to the addition of fibers resisting shear crack opening and sliding is visible in Fig. 4(a, c). The multiple shear cracking forms in a relatively high range of shear stresses (between 2.5 $\mathrm{MPa}$ and failure of the specimen). As previously noted, deformations of 'failure' shear cracks are plotted in graphs; however, this failure crack may not necessarily form as one of the first shear cracks in the beam.

The effect of varying shear angle is illustrated by comparing results in the left column (shear crack angles from $25^{\circ}$ to $35^{\circ}$ ) to results in the right column (shear crack angles from $40^{\circ}$ to $50^{\circ}$ ) in Fig. 4. For OC (Fig. 4(e, f)) with smaller shear crack angles $\left(25-35^{\circ}\right)$, failure occurs upon crack formation, while for larger crack angles $\left(40-50^{\circ}\right)$ immediately after crack formation the shear stress increases. 

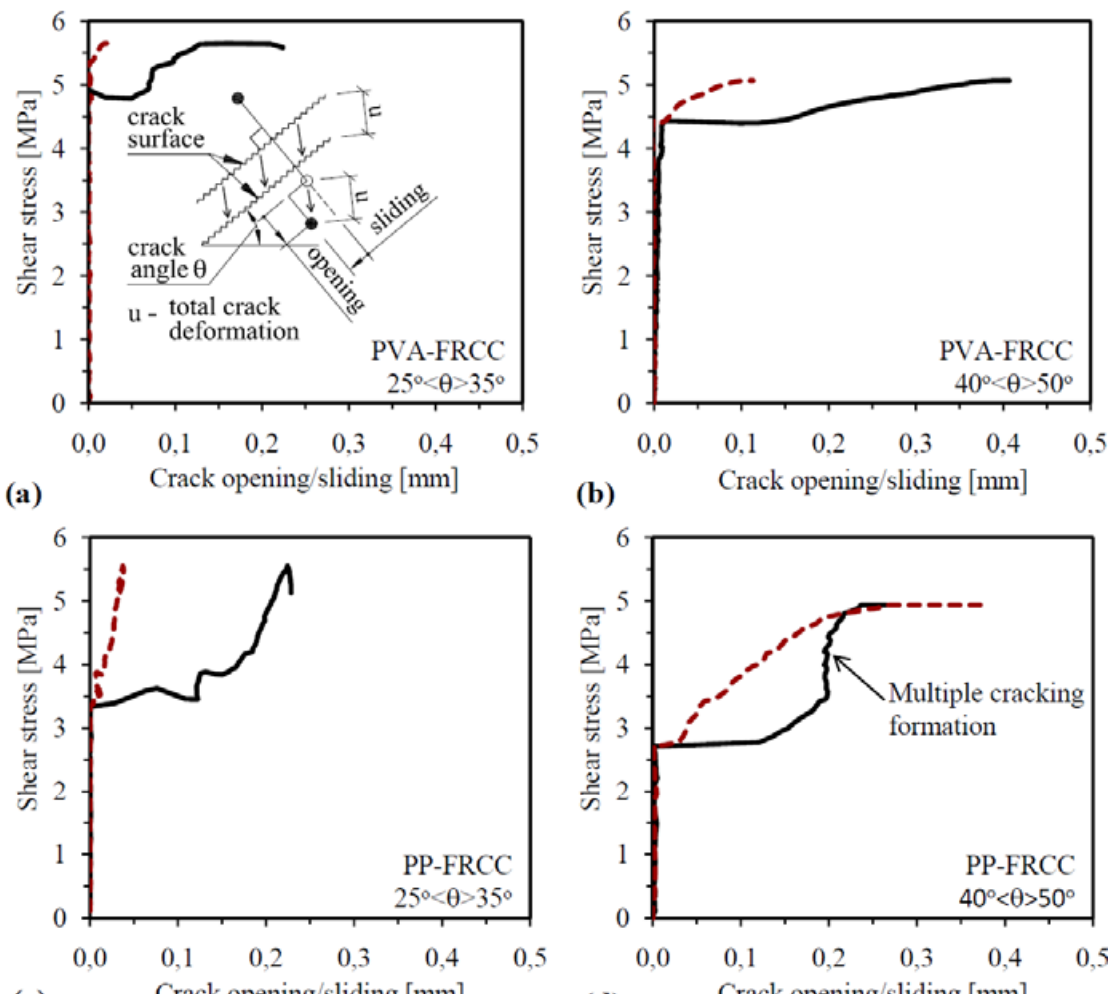

(c)

(d)
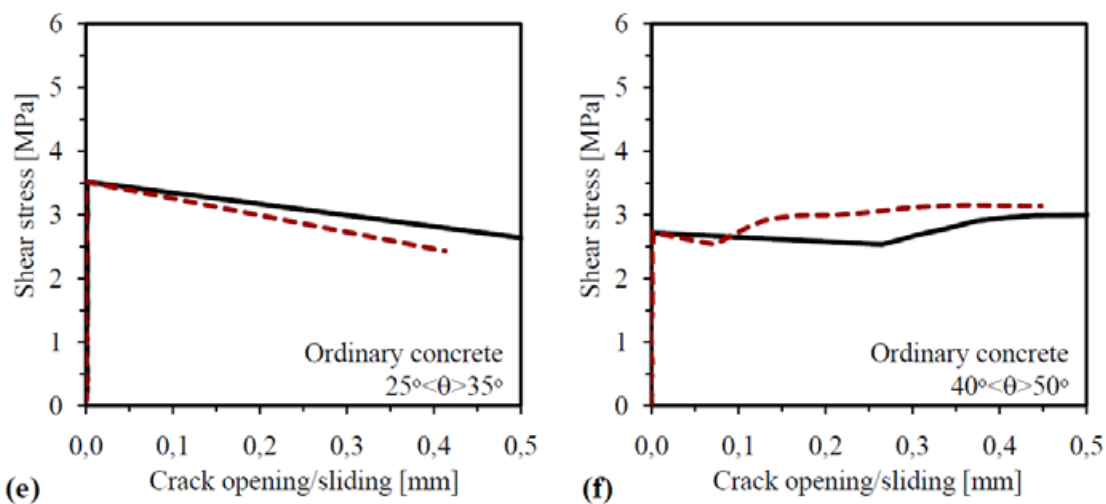

$$
\text { -------. Sliding }
$$

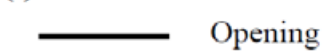

Fig. 4. Characteristic shear stress - crack opening and sliding displacement relationships for: (a) and (b) PVA-FRCC beams for crack angle $25-35^{\circ}$ and $40-50^{\circ}$, respectively; (c) and (d) PP-FRCC beams for crack angle $25-35^{\circ}$ and $40-50^{\circ}$, respectively; (e) and (f) ordinary concrete beams for crack angle $25-35^{\circ}$ and $40-50^{\circ}$, respectively. Schematic in (a) shows the definition of crack opening and sliding displacements 
For FRCC (Fig. 4(a-d)) regardless of shear crack angle, the shear stress increases significantly compared to $\mathrm{OC}$, but the results indicate that the shear crack angle also affects structural performance of FRCC. For smaller shear crack angles $\left(25-35^{\circ}\right.$, Fig. 4(a, c)), the sliding of cracks does not exceed $0.05 \mathrm{~mm}$, which is 4-6 times less than the opening, while much larger sliding deformations were obtained for steeper shear cracks $\left(40-50^{\circ}\right.$, Fig. 4(b, d)). Comparing PVA-FRCC to PP-FRCC with shear crack angle $25-35^{\circ}$ (Fig. $4(\mathrm{a}, \mathrm{c})$ ), the immediate crack opening was larger for PP-FRCC than in PVA-FRCC, due to reduced elastic modulus and softer interfacial bond with the cementitious matrix for PP fibers due to their hydrophobic nature. Comparing PVA-FRCC to PP-FRCC with shear crack angle 40-50 (Fig. 4(b, d)) crack openings were similar, but PP-FRCC exhibited larger crack sliding particularly at failure. For PP-FRCC the values for crack opening and sliding were similar in scale at failure, while for PVA-FRCC crack sliding was significantly smaller than the opening displacements at failure. Results indicate that the shear resistance of PP-FRCC and PVA-FRCC were similar, especially for steeper shear crack angles even though direct tensile properties were different (Fig. 2).

\section{Discussion}

Based on the results shown in Fig. 4, possible explanations of the mechanisms controlling shear cracking and failure have been developed as illustrated in Fig. 5. Fig. 5(a,b) shows how the shear crack angle influences aggregate interlock, which is the only crack bridging mechanism in OC. Assuming a constant total crack deformation (Fig. 4(a)), the steeper shear crack angle provides more contact of crack surfaces, increasing the potential for aggregate interlock. Fig. 5(c) shows a crack immediately after opening in FRCC, where in addition to the aggregate interlock fiber bridging contributes to the shear stress transfer. However, as shown in Fig. 5(d), with additional deformation the aggregate interlock is overcome and fibers exclusively bridge the crack. The effect of varying shear crack angle on FRCC is illustrated in Figs. 5(d, e), which show that reduced shear crack angles geometrically reduces sliding; therefore, the tensile properties of the fibers are emphasized. Fig. 6(a) illustrates the shear crack development mechanism for ordinary unreinforced concrete consisting of three stages:

1. Crack formation - Brittle fracture occurs, resulting in crack opening and relatively small crack sliding. The deformation is resisted primarily by aggregate interlock.

2. Aggregate interlock - Aggregate interlock can transfer relatively high stresses (higher than at first crack strength) if the crack opening is small.

3. Failure, loss of aggregate interlock - Aggregate interlock failure is dependent on aggregate sizes, crack opening, and shear crack angle. 


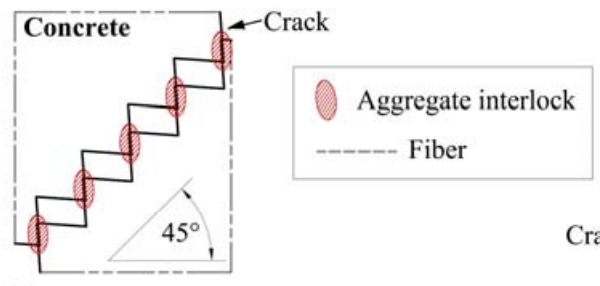

(a)
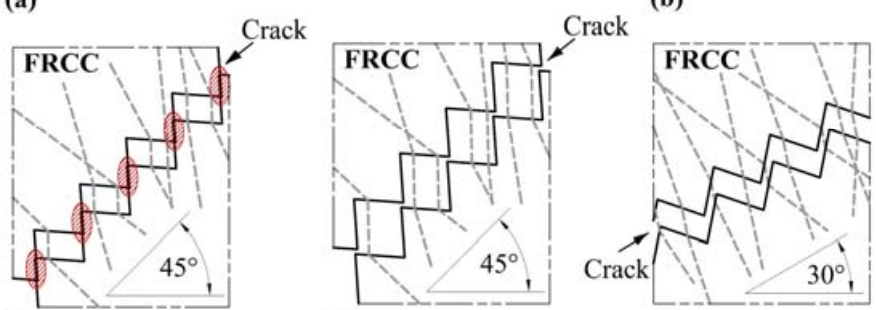

(c)

(d)

(e)

Fig. 5. Illustration of bridging mechanisms for OC with constant crack opening for (a) $45^{\circ}$ and (b) $30^{\circ}$ shear crack angle, and for FRCC (c) while aggregate interlock is acting and (d,e) while only fiber bridging is acting. In (d) a shear crack angle of $45^{\circ}$ is shown, while (e) has a $30^{\circ}$ angle

For FRCC, additional load can be transferred across cracks by fiber bridging. The shear crack behavior of FRCC with small aggregate sizes $(<0.18 \mathrm{~mm})$ can be characterized by the following four stages as illustrated in Fig. 6(b):

1. Crack formation - Brittle crack opening and minimal sliding (typically $<0.03$ $\mathrm{mm}$ ) are resisted by fiber bridging and aggregate interlock (Fig. 5(c)).

2. Crack opening and sliding are restrained by fiber bridging and aggregate interlock - Aggregate interlock and fiber bridging allow transfer of additional shear stresses across the crack (Fig. 5(c)). The effect of aggregate interlock is reduced as crack opening exceeds half of the maximum aggregate size.

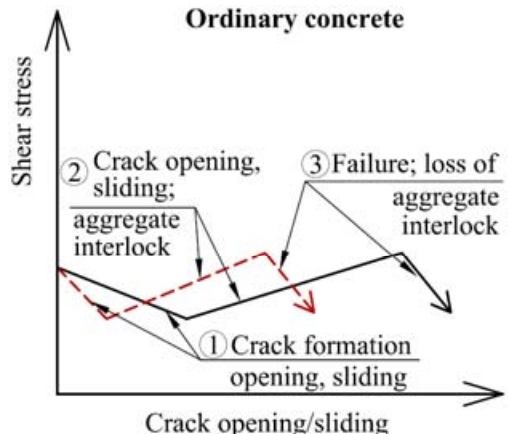

(a)

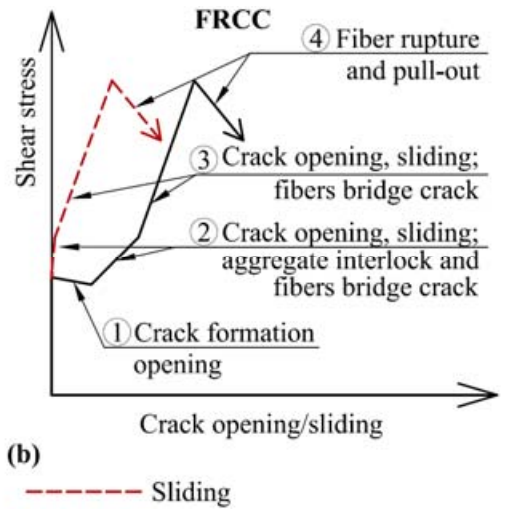

Fig. 6. Shear crack development mechanism for (a) plain concrete (OC) and (b) FRCC 
3. Fibers bridge crack and transfer shear stresses - As shown in Fig. 5(d, e), only the fibers bridge the crack, however, the transferred shear stress may continue to increase.

4. Fiber rupture and pull-out - Fibers start to rupture or pull-out. Additional deformation causes reduction in shear stress transfer and ultimately failure. Ductility of the FRCC is dependent on the stiffness of the cementitious matrix, fiber properties and bond properties between fiber and matrix.

Further, during stages 2 and 3 for FRCC, additional shear cracks may form due to their multiple cracking features, temporarily reducing the crack opening rate of the existing shear cracks. This mechanism is highlighted in Fig. 4(d).

\section{Conclusions}

Shear testing of ordinary concrete and fiber reinforced cementitious composite beams with PVA and PP fibers were carried out. Based on experimental results and photogrammetric documentation of the specimen deformations, fundamental descriptions of shear crack opening, sliding and subsequent failure for plain concrete as well as for FRCC are proposed. The benefits of using FRCC as a structural material for resisting shear loads are improved shear resistance and crack control. Results indicate that the shear resistance of PP-FRCC and PVA-FRCC were similar, especially for steeper shear crack angles, even though direct tensile properties differ between these two types of FRCC. The crack width control provided by FRCC is desirable from a structural and durability viewpoint.

\section{References}

[1] Choi, K., Park, H., Wight, J. "Shear strength of steel fiber-reinforced concrete beams without web reinforcement", ACI Structural Journal, 104, 12-21, 2007

[2] Kabele, P. "Fracture Behavior of Shear-Critical Reinforced HFRCC Members", Proc. on the 49th Int. RILEM Workshop on HPFRCC in Structural Applications, USA, 383-392, 2006

[3] Majdzadeh, F., Soleimani, S., Banthia, N. "Shear strength of reinforced concrete beams with a fiber concrete matrix" Canadian Journal of Civil Engineering 33(6), 726-734, 2006

[4] EN 12390-6 "Testing hardened concrete: Tensile splitting strength of test specimens", 2009

[5] Lárusson, L.; Fischer, G.; Jönsson, J. "Mechanical Interaction of ECC with Fiber Reinforced Polymer (FRP) rebar in tensile loading", ACM Conference. South Africa, 2009

[6] Li, V., et al. "On the Shear Behavior of Engineered Cementitious Composites" Adv. Cement Based Mat. 1(3), 142-149, 1994

[7] Li, V., Kanda, T. "Engineered Cementitious Composites for structural applications" Journal of Materials in Civil Engineering, 10, 66-69, 1998

[8] Fischer, G., Li, V., "Effect of fiber reinforcement on the response of structural members" Engineering Fracture Mechanics, 74, 258-272, 2007

[9] Naaman, A., Reinhardt, H. "High Performance Fiber Reinforced Cement Composites", RILEM Publications S.A.R.L., Proceedings PRO 6, France 2003 